\title{
Sugar, snacks and energy drinks in the spotlight
}

S ugar and its links to tooth decay and obesity continue to dominate news headlines as we begin 2018, and new campaigns are being launched that aim for improved oral and general health.

\section{Energy drinks}

A paper published in BMJ Open in December 2017 for the first time revealed the sugar, calorie and caffeine content of products marketed as 'energy drinks' sold in the UK between 2015 and 2017 (http://bit. ly/2BAzCUp). While the number of products available on the market in that period has fallen from 90 to 59, sugar, calorie and caffeine content remain high.
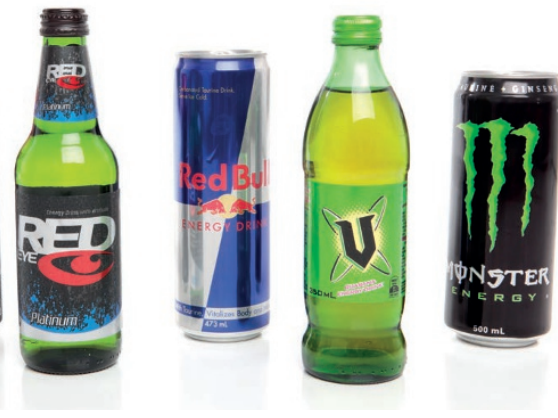

Certain manufacturers have started to reformulate ahead of the impending 'sugar tax' due in April 2018; the energy drinks surveyed show a $10 \%$ reduction in sugar from $10.6 \mathrm{~g}$ to $9.5 \mathrm{~g}$ per $100 \mathrm{ml}$ in the two-year period.

However, the study found that typical serving sizes of energy drinks are larger than other sugar-sweetened drinks, at $500 \mathrm{ml}$ (twice the standard serving). Furthermore, the average sugar content in energy drinks in both 2015 and 2017 (per serving) was more than an adult's entire maximum daily recommendation for sugar intake in the UK.

In 2015, Action on Sugar called for a ban on the sale of energy drinks to children. In November 2017, celebrity chef Jamie Oliver also announced that he would fight for new laws to stop children buying energy drinks.

On 12 January the British Society of Paediatric Dentistry (BSPD) added its voice in support of a ban on the sale of high energy drinks to under-16s. Claire Stevens, President of BSPD, said that energy drinks are 'doubly bad for teeth because these drinks have high levels of sugar and they are acidic. This means they can cause both dental decay and erosion of teeth'

The BSPD added that it was delighted that Waitrose has decided to refuse to sell energy drinks to children under 16 as of 5 March this year. Aldi, Sainsbury's, Asda and Morrisons have also pledged to start asking for ID before approving the sale of highly-caffeinated drinks.

\section{Healthier snacks}

On 2 January, Public Health England (PHE) launched the first Change4Life campaign promoting healthier snacks. The campaign encourages parents to 'look for 100 calorie snacks, two a day max' to reduce children's sugar intake. PHE said that half of children's sugar intake - currently around seven sugar cubes a day - comes from unhealthy snacks and sugary drinks, leading to obesity and painful tooth decay.

PHE's healthier snack suggestions include fresh or tinned fruit; chopped vegetables and lower fat hummus; plain rice cakes; crackers; malt loaf; lower fat cheese; small, low fat, lower sugar yoghurt; sugar free jelly; crumpets and Scotch pancakes.

PHE's improved Change4Life 'Food Scanner' app also shows parents how many calories, sugar, salt and saturated fat is in their food to help make healthier choices easier. It can be downloaded from the App Store or Google Play.

As part of the campaign dentists are being provided with a free dental toolkit to act as a springboard for a discussion about dental prevention with parents and families. All Chairs of Local Dental Networks have been notified about the toolkits and invited to encourage practices to apply early. 'Top Tips for Teeth' includes posters, leaflets, badges and a briefing guide (http://bit. ly/2nrmYBY).

\section{Perio and caries awareness}

On 11 January, the European Federation of Periodontology (EFP) launched the 'Perio and Caries' awareness campaign, in order to call attention to the growing burden of tooth decay and severe gum disease.

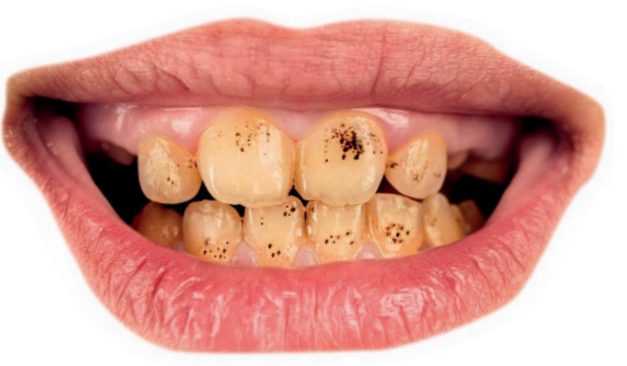

The campaign emphasises that caries and periodontal disease are the most common non-communicable diseases yet they are largely preventable, that they lead to tooth loss and that gum disease is linked to serious health issues such as diabetes, cardiovascular diseases and cancer.

The Perio and Caries initiative is directed towards dental and other health professionals, researchers, the public and policymakers. The 30 national societies that comprise the EFP will promote the campaign in their countries, with actions targeted at local communities and authorities. Recommendations are based on the consensus of over 75 experts in the field of periodontology and cariology who carefully analysed the existing scientific evidence during the EFP Perio Workshop 2016.

A dedicated website has been set up offering up to date information and recommendations, including infographics and key messages, all for stakeholders: perioandcaries.efp.org.

\section{Growth in tooth extractions}

New figures released on 13 January 2018 by the Local Government Association (LGA) revealed that there were 42,911 hospital operations to remove unhealthy teeth in children and teenagers in the last year, or 170 operations a day. 


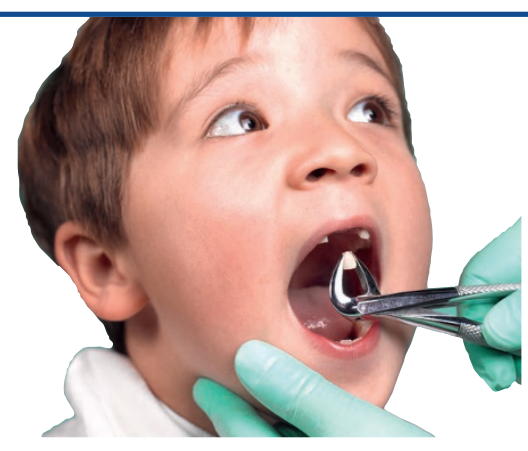

The Oral Health Foundation referred to the figures as 'appalling' and called for the Government to do more to help address the dangerous levels of sugar consumed by children in the UK, in addition to better oral health education for children and new water fluoridation schemes.

The extractions of multiple teeth in under-18s in England cost the NHS $£ 36.2$ million - a $17 \%$ increase on the 36,833 procedures carried out in 2012/13.

The British Dental Association (BDA) condemned ministerial indifference towards the new statistics. The Government's centrepiece policy 'Starting Well', aimed at improving oral health outcomes for 'high risk' children, has no new funding attached, and is operating in parts of just 13 local authorities in England. Activities in London are thought to cover just three wards in the Borough of Ealing.
BDA Chair Mick Armstrong said: 'This short-sightedness means just a few thousand children stand to benefit from policies that need to be reaching millions'.

\section{Sharing bags}

On 26 January Action on Sugar called for a complete ban on all confectionery price promotions and a sugar tax on all confectionery of at least $20 \%$. This follows a new product survey by the group of leading experts, based at Queen Mary University of London, who have exposed the high amounts of sugar in chocolate confectionery 'sharing' bags.

Of the 95 chocolate confectioneries surveyed, the 'sharing' bag with the highest amount of sugar per pack contained 29 teaspoons, four times an adult's maximum daily sugar intake - almost 1,000 calories.

At the time of data collection (December 2017 - January 2018) from six leading supermarkets, each retailer was actively offering price promotions on some sharing bags, which made them comparatively better value for money than smaller pack sizes.

A poll in The Grocer (www.thegrocer. co.uk) conducted in 2014 revealed that over one in five adults (22.1\%) do not share sharing bags, but consume them alone and in one sitting. This figure was even higher for 16 -24-year-olds at $35.7 \%$.

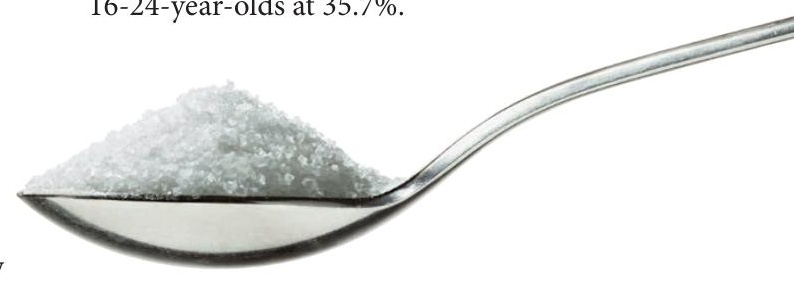

Action on Sugar said that consumption of confectionery is the second highest contributor to sugar intake in children, after soft drinks. If price promotions on high sugar products were removed, almost two teaspoons ( $7 \mathrm{~g}$ ) of sugar on average could be cut from every individual's diet per day.

\section{More infants seen in 2017}

In late January BSPD President Claire Stevens announced that 33,000 extra children aged 0-2 years old were seen in NHS general dental practices in England in the year to November 2017: extremely positive news for the BSPD's Dental Check by One (\#DCby1) campaign.

\section{Notice of elections to the Country Councils of the British Dental Association}

\section{Nominations are sought for election to the following council seats by 17.00 on Friday 9 March 2018.}

- English Council

- East Lancashire/East Cheshire (1 seat)

- Eastern Counties (1 seat)

- Metropolitan (1 seat)

- South Mercia (1 seat)

- West Lancashire/West Cheshire (1 seat)

- Northern Ireland Council

- Northern Ireland Branch (1 seat)

- Scottish Council

- East of Scotland Branch (1 seat)

${ }^{\circ}$ West of Scotland (1 seat)

- Welsh Council

- Swansea and West Wales Section

${ }^{\circ}$ Cardiff and South East Wales Section

${ }^{\circ}$ North Wales Section

Councils have the following remit:

- To provide regular advice and comment to the Principal Executive Committee as a consultative committee
- To consider and advise the Principal Executive Committee on all matters relating to dentistry within their country

- To advise the Principal Executive Committee on all aspects of policy within their country, facilitating external expert and member input to policy formation where required

- To receive regular reports from the Principal Executive Committee, to enable the Council to debate and comment on the activities of the Principal Executive Committee

- To liaise with branches and sections

- Elected members of country councils will be called upon to form an Interim Principal Executive Committee, if the Principal Executive Committee resigns, is dissolved, or becomes inquorate. This means they temporarily take responsibility as Directors of the Association and direction of the Association as a trade union in these circumstances, until fresh elections are completed.
The Country Councils play a vital role in ensuring that the Principal Executive Committee, which is concerned with the strategic direction and governance of the Association, is kept in touch with the views and concerns of members. Country Council members are the voice of members' to the Principal Executive Committee and senior management team.

The Country Councils together constitute the United Kingdom Council which, amongst other functions, considers an annual report from the Principal Executive Committee on its strategic priorities and activities.

\section{Term of office}

This shall be until autumn 2020, with the entitlement to stand for a further three year term of office at that point. More information about this and other BDA elections can be found at: www.bda. org/elections. 